\title{
IMPACTOS DA PRIVATIZAÇÃO DOS SERVIÇOS NO ATENDIMENTO AOS DIREITOS À ÁGUA E AO SANEAMENTO À LUZ DOS TRATADOS INTERNACIONAIS E LEGISLAÇÃO BRASILEIRA
}

\author{
IMPACTS OF PRIVATIZATION OF SERVICES IN MEETING THE RIGHTS TO \\ WATER AND SANITATION IN LIGHT OF INTERNATIONAL TREATIES AND \\ BRAZILIAN LEGISLATION
}

\begin{abstract}
Érika Alves Tavares Marques ${ }^{(1)}$
Grupo de Gestão Ambiental - UFPE. Doutora em Desenvolvimento e Meio Ambiente - PRODEMA/UFPE. Mestra em Tecnologia Ambiental pelo ITEP. Especialista em Gestão e Controle Ambiental pela UPE. Bióloga pela UFRPE.

Bianca Caroline Bortolin ${ }^{(2)}$

Doutoranda em Geografia pelo Programa de Pós-Graduação em Geografia da UNESP. Graduanda em Pedagogia pela Universidade da Cidade de São Paulo. Mestre em Geografia pela UNESP. Licenciada e Bacharelada em Geografia pela UNESP. Membro do Laboratório de Análise Espacial em Políticas Públicas (LAPP)/CEAPLA/IGCE/UNESP Rio Claro. Gabriela Lobato ${ }^{(3)}$

Médica Veterinária Sanitarista. Doutoranda em Saúde Pública ENSP/Fiocruz. Vice-Presidência de Ambiente, Atenção e Promoção da Saúde/ Fundação Oswaldo Cruz.
\end{abstract}

E-mail ${ }^{(1)}$ : erikatmbio@gmail.com.

\section{RESUMO}

O reconhecimento da água como direito humano à vida digna implica que o Estado deva ser responsabilizado pelo seu provimento para a população. Nesse contexto, os países signatários dos pactos de direitos internacionais, como o Brasil, têm a obrigação de respeitar e criar as condições para cumprir esse direito. O objetivo desse estudo é discutir sobre a questão da água como direito humano e a privatização dos serviços A abordagem da pesquisa é quali-quantitativa e baseada em pesquisa bibliográfica e coleta de dados primários e secundários. Mesmo que em ritmo lento, as coberturas de água e de esgoto têm melhorado nos últimos anos no Brasil, porém 35 milhões de brasileiros ainda não têm acesso a água tratada e quase 100 milhões de pessoas utilizam medidas alternativas para lidar com seus dejetos. Percebe-se que a privatização, ao contrário do que é noticiado, vem para atender aos anseios de grupos organizados.

\begin{abstract}
The recognition of water as a human right to a decent life implies that the State must be held accountable for its provision to the population. In this context, the signatory countries of international rights pacts, such as Brazil, have the obligation to respect and create the conditions to fulfill this right. The aim of this study is to discuss the issue of water as a human right and the privatization of services. The research approach is quali-quantitative and based on bibliographical research and primary and secondary data collection. Although at a slow pace, water and sewage coverage have improved in recent years in Brazil, however 35 million Brazilians still do not have access to treated water and nearly 100 million people use alternative measures to deal with their waste. It is noticed that privatization, contrary to what is reported, comes to meet the wishes of organized groups.
\end{abstract}

Palavras-chave: Regulação. Qualidade de água. Privatização. Saneamento. Direitos humanos.

Key words: Regulation. Sewage. Potable water. Economic accessibility. Privatization.

\section{INTRODUÇÃO}

Em 2010, a Assembleia Geral da Organização das Nações Unidas por meio da Resolução 64/A/RES/64/292, de 28 de julho daquele ano, reconhece o direito de acesso à água potável e ao saneamento como direito humano essencial, fundamental e universal, portanto indispensável à vida 
com dignidade e reconhecido como "condição para o gozo pleno da vida e dos demais direitos humanos", ou seja, o saneamento básico propicia vida saudável e com qualidade e, com isso, promove a dignidade da pessoa humana (LIMA, 2020).

O acesso à água potável e ao saneamento são direitos humanos fundamentais, previstos no direito e nas convenções internacionais (ONU, 2018). Esse direito humano fundamental é violado em grande parte do planeta, que abriga, atualmente, 2,2 bilhões de pessoas carentes de saneamento básico. Conforme estudo publicado em 2018, com base em dados de 2015, pela Comissão Econômica para a América Latina e o Caribe (CEPAL), o acesso à água e ao esgotamento sanitário é $18 \%$ maior entre os $20 \%$ mais ricos da população brasileira do que entre os $20 \%$ mais pobres.

A resolução da ONU, por não ser uma lei em sentido formal e material, não tem o condão de obrigar as nações a se responsabilizarem pela implementação de políticas públicas de saneamento, no entanto traduz-se como efetiva recomendação aos Estados para que destinem recursos financeiros e promovam o "fortalecimento de capacidades e a transferência de tecnologia por meio de assistência e cooperação internacional, em particular aos países em desenvolvimento, a fim de intensificar esforços para fornecer a toda a população acesso econômico à água potável e saneamento" (LIMA, 2020).

Havendo compromisso formal dos Estados com esse direito, cria-se pressão internacional para repensar noções, tais quais disponibilidade, qualidade e acessibilidade à água, e a considerar questões como segurança, higiene e custo. Porém, apesar do compromisso público assumido, para ter força de lei, o direito humano à água precisa ser incorporado às leis internas de cada país. Assim, apesar do reconhecimento do direito humano à água existir, só valerá enquanto direito naquelas nações que o validaram como tal (POLITIZE, 2021).

O acesso à água potável e ao saneamento básico constitui o Objetivo de Desenvolvimento Sustentável 6 (ODS), da Agenda 2030, plano de ação organizado pelas Nações Unidas, externando o compromisso em garantir a universalização até 2030. Os prestadores de serviços e as entidades reguladoras têm papel central a desempenhar para garantir que os objetivos de abastecimento da água para consumo humano, do saneamento e de águas residuais, definidos no ODS 6 sobre a água e o saneamento, sejam cumpridos até 2030 (BOS et al., 2017).

Quando se fala em saneamento básico, a palavra de ordem é a universalização do acesso aos serviços públicos que integram esse componente indispensável à dignidade da pessoa humana, sobretudo diante do cenário mundial de escassez e desigualdades na disponibilidade, execução e qualidade dos serviços de saneamento (MACEDO, 2020).

O processo de urbanização no Brasil intensificou-se nos últimos anos, e desencadeou sérios problemas socioambientais e econômicos. Vale ressaltar que os espaços ocupados em centros urbanos e regiões metropolitanas são produtos do desmatamento de grandes áreas e resultam na impermeabilização dos solos, na poluição de lençóis freáticos, lâminas d'água superficiais, aumento de rejeitos sólidos, entre outros problemas ambientais, que provocam danos à saúde humana de modo geral (FAUSTINO et al., 2014).

As mudanças no meio ambiente têm intensificado a preocupação com a questão da alocação e qualidade dos recursos hídricos nas formulações de políticas públicas em nível nacional e em nível de planejamento regional e local.

Ainda que a Constituição brasileira não contemple o saneamento básico como direito humano fundamental, suas características de universalidade, essencialidade e fundamentalidade imprimem tal chancela. A ideia de a água potável ser considerada direito humano fundamental parte de suas funções de essencialidade para a vida de todas as pessoas, devendo ser tratada pelo Direito a partir de, pelo 
menos, duas perspectivas, quais sejam, como direito fundamental e como sujeito de direitos (CARLI, 2003).

Assim, sendo o saneamento básico considerado como um conjunto de medidas que visam preservar ou modificar as condições do meio ambiente com a finalidade de prevenir doenças e promover a saúde, é plenamente justificável sua inserção no rol dos direitos fundamentais, uma vez que não há como dissociá-lo da saúde, pois o saneamento é meio para a obtenção da saúde em toda sua plenitude. Tanto para o abastecimento de água para consumo humano como para os serviços de saneamento, aplicam-se os critérios normativos dos direitos humanos: disponibilidade, qualidade e segurança, aceitabilidade, acessibilidade física e acessibilidade econômica. Para nenhum desses critérios existem valores absolutos que se apliquem globalmente; os governos terão de estabelecer metas nacionais e locais (BOS et al., 2017).

O objetivo deste estudo é discutir sobre a privatização dos serviços e seus impactos na qualidade, nas tarifas praticadas e no atendimento aos direitos humanos à água e ao saneamento.

\section{MATERIAL E MÉTODOS}

A abordagem da pesquisa é quali-quantitativa e a metodologia está fundamentada em duas vertentes: 1) Pesquisa bibliográfica com base em artigos e estudos científicos publicados sobre qualidade da água, privatização, saneamento e direitos humanos.

\section{RESULTADOS E DISCUSSÃO}

\subsection{Privatização dos serviços e o atendimento aos direitos humanos à água e ao saneamento}

Em 1948, a Assembleia Geral das Nações Unidas publicou a Declaração dos Direitos Humanos, na qual os Direitos Humanos à Água e ao saneamento (DHAS) não eram explícitos. O Pacto Internacional sobre Direitos Econômicos, Sociais e Culturais (PIDESC) foi adotado em 1966, consagrando os direitos econômicos, sociais e culturais dentro do enquadramento internacional de direitos humanos. Tanto a declaração de 1948 quanto o PIDESC preveem o direito humano de todas as pessoas a um nível de vida adequado, incluindo à alimentação, vestimenta e moradia (ALBUQUERQUE, 2014).

Com o agravamento da crise hídrica e de saneamento no mundo, principalmente no século XX, várias organizações dos direitos humanos e do desenvolvimento passaram a dar maior importância ao direito à água e ao saneamento. Assim, tratados internacionais começaram a explicitar a importância desses direitos. Porém, só em 2010, após a publicação da relatora especial da ONU, que destacava as obrigações de direitos humanos relacionadas ao saneamento, que a Assembleia Geral da ONU reconhece os DHAS (ALBUQUERQUE, 2014).

O PIDESC determina que os Estados têm que caminhar em direção à total realização dos direitos à água e ao saneamento, usando o máximo possível de recursos disponíveis . Entende-se que o alcance desses direitos pode levar muitos anos, mas a lentidão do processo não deve ser usada como desculpa para a falta de investimento, mesmo durante crises econômicas e financeiras. A realização progressiva dos direitos econômicos, sociais e culturais é, portanto, um processo gradual e contínuo.

O Estado ainda tem o dever de proteger, cumprir e respeitar os DHAS, ou seja, deve impedir que terceiros impeçam as pessoas de usufruírem seus direitos; não podem impedir que as pessoas desfrutem dos DHAS e tem que garantir a criação de condições para que todos tenham acesso aos seus direitos. Aliado a isso, os princípios de direitos humanos de não discriminação e igualdade, 
acesso à informação, participação e prestação de contas devem ser assegurados no contexto da realização de todos os direitos humanos, não apenas os direitos humanos à água e ao saneamento (ALBUQUERQUE, 2014).

No Brasil, a Emenda Constitucional $n^{\circ}$ 90/2015, alterou o artigo $6^{\circ}$ da Constituição Federal, estabelecendo como direitos sociais a educação, a saúde, a alimentação, o trabalho, a moradia, o transporte, o lazer, a segurança, a previdência social, a proteção à maternidade e à infância e a assistência aos desamparados (BRASIL, 2015). Assim, ainda não temos o direito à água e ao saneamento como um direito explícito na constituição, porém, estando os direitos à alimentação, saúde e moradia garantidos, temos os direitos do acesso à água de qualidade e ao saneamento básico implícitos. Ainda segundo Freire (2020), sobre a "constituição é possível chegar às seguintes conclusões acerca dos serviços de saneamento básico: (i) trata-se de objeto de política urbana; (ii) quando os serviços de saneamento básico forem voltados aos administrados em geral, serão serviços públicos, já que são de titularidade pública; (iii) as políticas de saneamento básico são instrumentos para a efetivação do direito à saúde".

Apesar de ser um dever do Estado, nada impede que este delegue os serviços de água e saneamento básico a atores privados e isso tem trazido grande preocupação e sofrido muita oposição de parte da comunidade dos direitos humanos. Outra vertente defende a neutralidade, em que o importante é que os serviços sejam bem prestados, independentemente se pelo ente privado ou público. Por isso, esse tema foi mote de relatório específico do relator especial da ONU para os DHAS, em 2020. Nesse documento, o relator discorre sobre os riscos que podem ser agravados pela privatização e identifica as salvaguardas necessárias para proteger os DHAS (ONU, 2020). A publicação vem no momento de escalada da desestatização no Brasil, que experimenta uma onda de privatizações do setor sem precedentes, na contramão mundial, em que muitas experiências de privatização estão sendo revistas e revertidas.

O relatório chama atenção para o fato de que a privatização tem sido vista como solução dos problemas com a redução do papel dos Estados, mas que em momentos de crise sociais e econômicas, só quem pode garantir o fornecimento desses serviços e proteger a população mais vulnerável é o próprio Estado. Vide o que estamos presenciando na pandemia de Covid-19, em que o Estado intervém com a suspensão da cobrança de água, proibição dos cortes e reconectando as pessoas aos serviços (ONU, 2020).

Privatização é uma prática que consiste em transferir, por prazo indeterminado, as empresas públicas ao controle da iniciativa privada, ou seja, tirando do Estado a função de gerir e controlá-las. A concessão é a transferência temporária da gestão das atividades empresariais do Estado à iniciativa privada, mas a titularidade dessas empresas permanece do Estado. Existe ainda um modelo intermediário, a Parceria Público-Privada (PPP), que consiste em contratos de prestação de serviços de médio e longo prazo (de 5 a 35 anos), firmados pela administração pública, em todas as esferas (EOS, 2021).

Os fatores de riscos que podem ser agravados pela privatização são baseados em uma combinação de três fatores: maximização do lucro, monopólio natural - que caracteriza a prestação dos serviços de água e saneamento básico - e desequilíbrio de poder. Os prestadores privados, claro, visam lucro, que vem por diminuição de custos (diminuição de investimento, por exemplo) ou aumento da receita. Neste caso, pressionar autoridades públicas para revisão de tarifas seria uma maneira. A água é um monopólio natural, operado por somente um prestador, assim os órgãos reguladores estão mais expostos ao risco de captura por prestadores. Por último, como as concessões são, geralmente, feitas por entes locais, muitas vezes esses carecem de conhecimento técnico, estrutura, força política e financeira para que todo o processo, desde a contratação até a supervisão possa ser feito, o que acarreta um desequilíbrio de poder importante entre a empresa privada e o ente público. 
Baseado nesses fatores de risco, a ONU (2020) afirma que a "privatização no setor de água $e$ saneamento básico leva a um conjunto único de riscos para a realização dos direitos humanos." Entre os riscos mais importantes, são elencados: uso do máximo de recursos disponíveis; acessibilidade financeira; nenhuma melhoria ou deterioração dos serviços; sustentabilidade; acesso à informação, participação e responsabilização.

A realização progressiva dos direitos econômicos, sociais e culturais posta no PIDESC é obrigação dos Estados e fica sob risco: se as empresas privadas transferirem seu lucro para outro setor, que não o de água, sem os correspondentes ganhos de eficiência e acesso; se tem limitação de investimentos com recursos próprios, particularmente em áreas onde as pessoas vivem em situações vulneráveis; quando faz uso de práticas corruptas e ainda em casos de concessões, nas quais o pagamento pela outorga não é aplicado no setor de água e saneamento básico. Como exemplo, no caso da privatização da Companhia Estadual de Águas e Esgotos do Rio de Janeiro (Cedae), o investimento previsto para as áreas de favelas é de apenas 1,7 bilhão de real para a ampliação do sistema de abastecimento de água e de saneamento básico, o que corresponde a somente 5,7\% do total de investimentos a serem realizados ao longo dos 35 anos de concessão (RAMOS e BRITTO, 2021).

Se o objetivo da privatização é levar um serviço de melhor qualidade, acesso e com maior investimento do que quando prestado pelo ente público e, além disso, deve produzir lucro, em teoria esse serviço será mais caro. Por isso, a acessibilidade financeira é um problema em casos de desestatização. Apesar da definição tarifária geralmente ser feita por autoridades públicas, as empresas, além do interesse em aumentar receita por meio de tarifas e taxas, dispõem de conhecimento técnico e recursos que, na maior parte das vezes, superam os dos governos locais. Essa condição só aumenta o risco de preços inacessíveis para os pobres, especialmente onde não há políticas públicas de subsídios. E, claro, "é mais provável que os prestadores públicos sejam mais receptivos ao ver os usuários como detentores de direitos e não os desconectem tão facilmente como em situações em que a prestação é voltada para o lucro" (ONU, 2020).

O aumento da qualidade dos serviços é um argumento comumente encontrado na defesa da privatização, porém evidências sugerem que essa afirmação nem sempre procede. Isso porque os interesses comerciais geralmente precedem aos sociais e, mesmo com os serviços privatizados, é o Estado que permanece responsável pelos direitos dos cidadãos.

Ferreira e Neves-Silva (2021) concluíram que "as empresas privadas atuam em municípios mais populosos, com melhor IDH e renda per capita, e com maior porcentagem da população morando em área urbana." Condições estas que favorecem a busca pelo lucro e, quando isso acontece, o impacto na sustentabilidade dos serviços de água e saneamento básico fica comprometido, consequentemente, os DHAS. Exemplo citado no relatório é a crise hídrica que atingiu a região metropolitana de São Paulo, em 2014, região atendida por uma empresa de capital misto e que tinha conhecimento, desde 2009, da necessidade de investimento para evitá-la, mas o necessário não foi feito e os dividendos foram pagos aos acionistas.

A falta de transparência pode percorrer todo o processo de privatização, desde a tomada de decisão até o monitoramento do desempenho dos prestadores devido à dificuldade de acesso à informação. Tem-se ainda, em alguns casos, problemas com a transparência financeira e comercial dessas empresas.

Ficou demonstrado por Guimarães (2012), em Campos de Goytacazes-RJ, que o simples fato de um dado município outorgar a concessão de oferta do serviço público de água para a iniciativa privada não se traduz necessariamente na ampliação da cobertura dentro de padrões de eficiência, volume e qualidade de água distribuída e nem garante a equidade no atendimento ao conjunto da população. 
Como citado, a obrigação de respeitar, proteger e cumprir os direitos humanos é do Estado, porém se este terceiriza um serviço como o acesso à água e ao saneamento, o marco dos DH exige que se estabeleçam medidas preventivas para evitar impactos no seu cumprimento. Por isso, o relator para os DHAS da ONU elaborou recomendações aos Estados, empresas e organizações internacionais envolvidas em processos de privatização, resumidas na Quadro 1.

Quadro 1: Recomendações aos Estados, empresas e organizações internacionais envolvidas em processos de privatização.

\begin{tabular}{|c|c|c|}
\hline ndações aos & 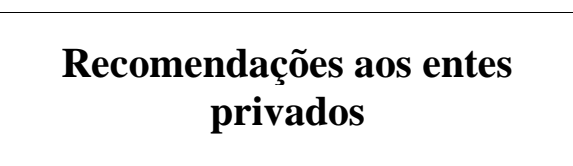 & $\begin{array}{r}\text { Recc } \\
\text { institu } \\
\text { in }\end{array}$ \\
\hline $\begin{array}{l}\text { *Adotar legislação que declare } \\
\text { explicitamente os DHAS; } \\
\text { *Manter o mesmo nível de } \\
\text { obrigações dos prestadores } \\
\text { públicos aos privados; } \\
\text { *Conduzir avaliação de DH que } \\
\text { inclua as alternativas } \\
\text { disponíveis antes de optar pela } \\
\text { privatização; } \\
\text { *Escolher tipo de prestação de } \\
\text { serviço mais adequado e } \\
\text { adaptado às condições locais; } \\
\text { *Estabelecer mecanismos de } \\
\text { responsabilização e aplicação } \\
\text { da lei eficazes e transparentes e } \\
\text { medidas para garantir que as } \\
\text { alegações de violação dos DH } \\
\text { por parte de prestadores } \\
\text { privados sejam devidamente } \\
\text { investigadas e sancionadas; } \\
\text { *Promover a participação ativa, } \\
\text { livre e significativa da } \\
\text { sociedade civil; } \\
\text { *Identificar conflitos potenciais } \\
\text { entre a legislação comercial e de } \\
\text { investimento e a legislação de } \\
\text { DH e os equacionar de forma } \\
\text { que esteja em conformidade } \\
\text { com suas obrigações; } \\
* \text { a co }\end{array}$ & $\begin{array}{l}\text { *Incorporar obrigações para } \\
\text { cumprimento dos DH, mesmo } \\
\text { quando não estipuladas na } \\
\text { legislação nacional; } \\
\text { *Identificar e abordar } \\
\text { proativamente as preocupações } \\
\text { com os DH; } \\
\text { *Comunicar ao público as } \\
\text { maneiras pelas quais a empresa } \\
\text { garante que seus interesses } \\
\text { comerciais sejam conciliados } \\
\text { com a realização dos DHAS; } \\
\text { *Abster-se de agir em } \\
\text { desrespeito ao conteúdo } \\
\text { normativo dos DHAS como } \\
\text { desconectando usuários que não } \\
\text { podem pagar suas contas ou } \\
\text { fornecendo serviços } \\
\text { seletivamente e investindo em } \\
\text { infraestrutura para setores da } \\
\text { sociedade mais capazes de pagar } \\
\text { tarifas; } \\
\text { *Divulgar a } \\
\text { financeiras e operacionais ao } \\
\text { público de maneira acessível, de } \\
\text { modo que os governos e a } \\
\text { sociedade civil possam } \\
\text { supervisionar de forma } \\
\text { abrangente o desempenho dos } \\
\text { serviços. }\end{array}$ & 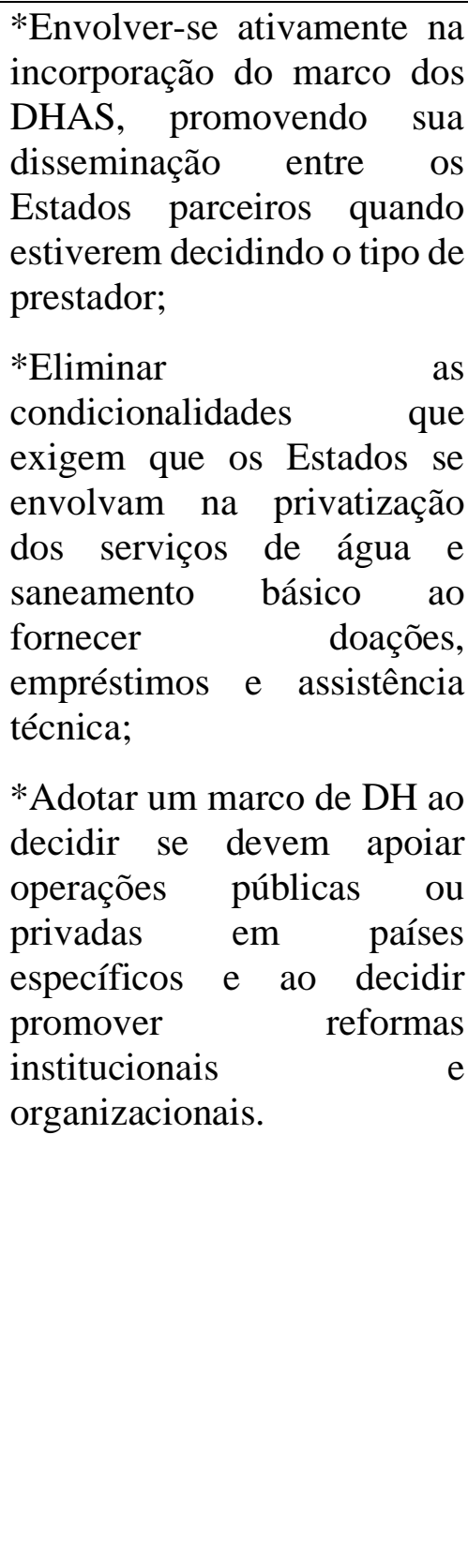 \\
\hline
\end{tabular}



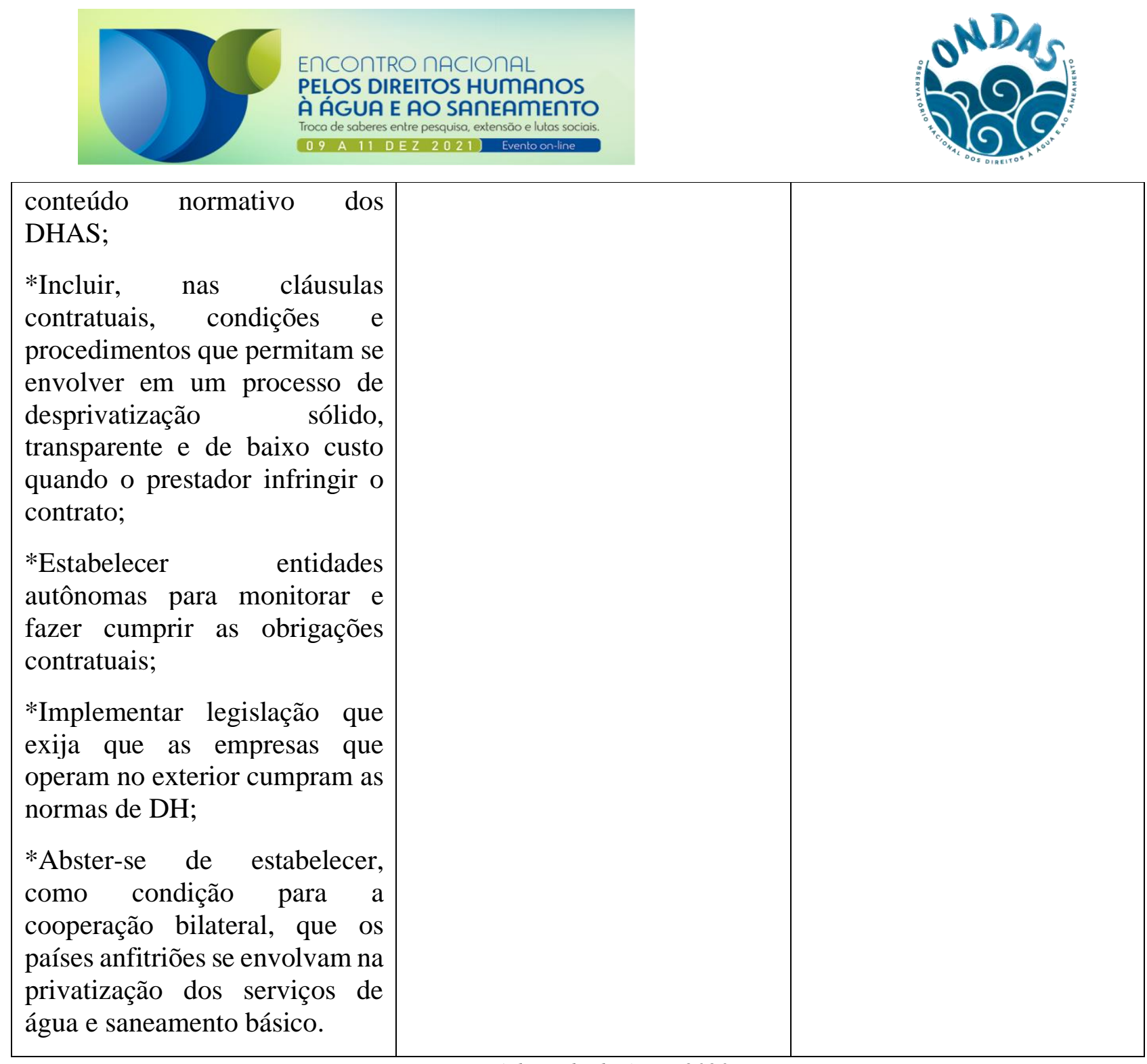

Fonte: Adaptado de ONU, 2020

Em muitas cidades médias e grandes, a questão do acesso à água potável e ao tratamento de esgotos é objetivamente um gargalo para o estabelecimento de uma sociedade que seja social e ambientalmente sustentável. Isso é especialmente crítico para debates em relação ao futuro das cidades, dadas as crescentes evidências de degradação e poluição de rios e nascentes e da contaminação das águas subterrâneas por diferentes formas. Nesse sentido, o Quadro 1 implica na real possibilidade de que haja exacerbação dos conflitos em torno de interesses socialmente divergentes no tocante ao acesso à água (GUIMARÃES, 2012).

\subsection{Privatização dos serviços e seus impactos na qualidade}

Por uma questão de princípio e definição, a água para consumo humano deve ser livre de agentes patogênicos e níveis tóxicos de produtos químicos. Para questões relacionadas ao critério da qualidade/segurança da água, estão referenciadas, como documentos de suporte para os DHAS, as diretrizes da Organização Mundial da Saúde para a Qualidade da Água para Consumo Humano (OMS, 2011a). A segurança absoluta é meta ambiciosa. Na vida real, é impossível eliminar todos os perigos associados à água e seus riscos inerentes para a saúde. Os níveis aceitáveis de risco estão associados à aceitabilidade social e à capacidade econômica para geri-los (BOS et al., 2017).

Segundo a Organização Mundial de Saúde (OMS), saneamento é o controle de todos os fatores do meio físico do homem que exercem ou podem exercer efeitos nocivos sobre o bem-estar físico, mental 
e social. De outra forma, pode-se dizer que saneamento caracteriza o conjunto de ações socioeconômicas que tem por objetivo alcançar salubridade ambiental. A utilização do saneamento como instrumento de promoção da saúde pressupõe a superação dos entraves tecnológicos, políticos e gerenciais que têm dificultado a extensão dos benefícios aos residentes em áreas rurais, municípios e localidades de pequeno porte (RIBEIRO e ROOKE, 2010).

O Brasil é um país classificado como emergente e está entre as maiores economias do mundo, mas ao se tratar de saneamento básico ocupa a $112^{\mathrm{a}}$ posição em um conjunto de 200 países. Percebe-se que os serviços de saneamento não se equilibram com a realidade de um país que possui destaque global. A falta de um sistema que envolva o saneamento básico gera vários problemas, os quais têm afetado diretamente a sociedade brasileira como, por exemplo: acondicionamento inadequado do lixo, má qualidade da água, disposição de dejetos em lugares inadequados, além de ambientes poluídos (COSTA e PINHEIRO, 2018).

No que diz respeito às questões de abastecimento, o Brasil possui um dos maiores números em quantidade e disponibilidade de água. Contudo, sabe-se que essa oferta está localizada em lugares com menor quantidade de pessoas. Em contrapartida, a alta densidade populacional está concentrada nos centros urbanos, exigindo maior oferta dos recursos hídricos e, na maioria dos casos, impactados pela degradação ambiental, consequentemente atingindo a qualidade da água e causando problemática para o abastecimento em grandes cidades (CAETANO, 2016). Mesmo o Norte, estando em região de localização privilegiada por duas grandes bacias hidrográficas, existe pouco acesso à água potável. Essa realidade está presente em localidades da Amazônia brasileira: Acre, Amazonas, Amapá, Pará, Rondônia, Roraima e Tocantins (BORDALO, 2017).

Dados sobre o saneamento, em 2019 (SNIS), demonstram que o Brasil possui população de 210,1 milhões de habitantes, sendo que 178 milhões estão localizados na área urbana e 32,1 milhões vivem na área rural $(15,28 \%)$. O Índice de Atendimento Total de Água (IATA) varia de 57,5\% (região Norte) a 91,9 \% (região Sudeste), conforme a região (Figura 1A). Com relação ao Índice de Atendimento Total de Esgoto (IATE), os resultados dos indicadores são muito aquém dos resultados referentes ao IATA, variando de $12,3 \%$ na região Norte a $79,5 \%$ na região Sudeste.

Figura 1: Índice de abastecimento total de água (A) e de esgoto (B).
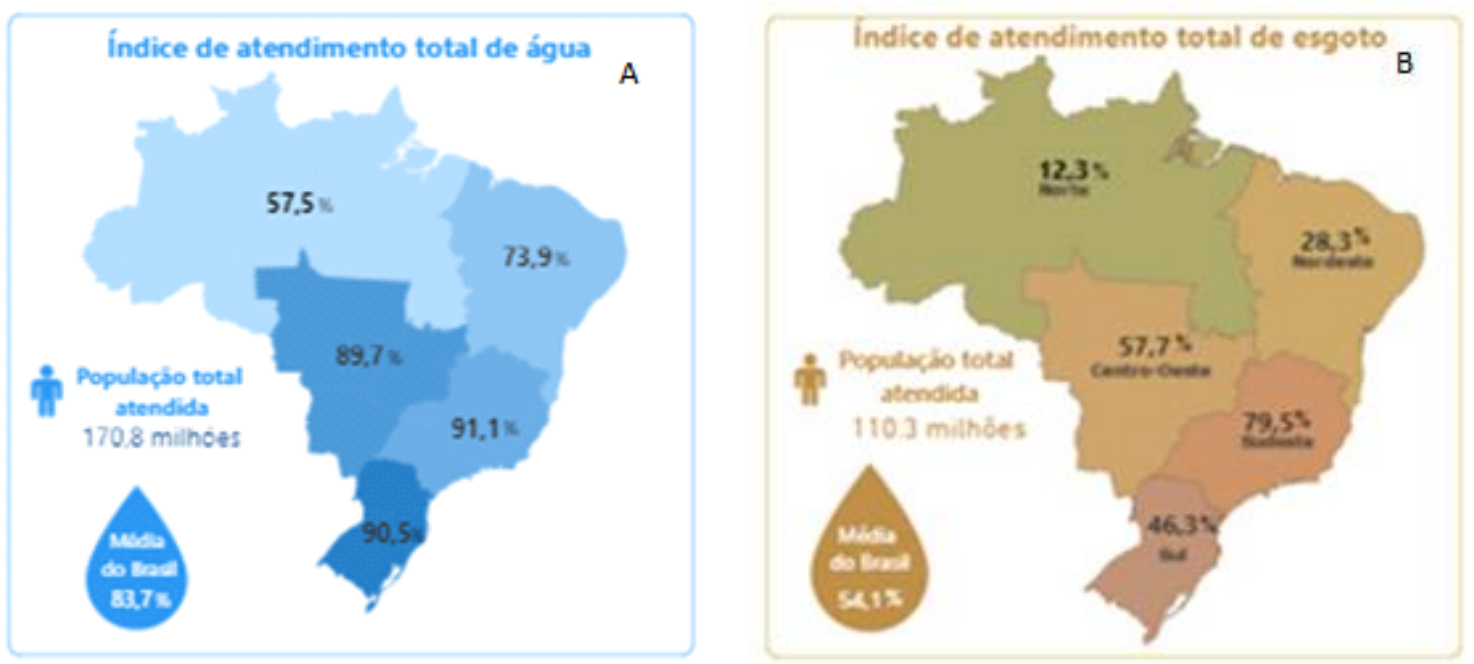

Fonte: SNIS, 2019 
As ações propositivas e necessárias para construir a segurança hídrica - no qual se insere integralmente os serviços de saneamento - podem ser estruturadas em quatro componentes, conforme a ONU/PNUD (2014): a) o acesso à água em quantidade e qualidade adequadas para garantir a vida e o bem-estar humano, que em essência é o papel do serviço de saneamento; b) o acesso à água para o desenvolvimento das atividades produtivas; c) o controle da poluição e compatibilização da água para diversos fins; d) a redução dos riscos associados aos eventos críticos. O conceito de segurança hídrica é o objetivo central da Política Nacional Brasileira de Recursos Hídricos (Lei Federal $\mathrm{n}^{\circ}$ 9.433/1997).

O ponto de partida para ampliar a segurança hídrica no longo prazo é a compreensão da exposição e da sensibilidade de cada região a um determinado conjunto de impactos e a formulação de respostas na forma de políticas e investimento visando reduzir essas vulnerabilidades (WORLD BANK, 2011).

A prestação dos serviços de saneamento básico pelo Estado - e daí sua qualificação como serviço público clássico - advém desde o início do século XX. Na década de 1930, surgiram as primeiras iniciativas nesse sentido, financiadas essencialmente por recursos da União. A forma pela qual o setor de saneamento está hoje estruturado em território nacional carrega, sem dúvida, marcante herança do Plano Nacional de Saneamento (PLANASA).

A Lei Federal n ${ }^{\circ}$ 11.445/2007 criou o Plano Nacional de Saneamento Básico (PNSB), com diretrizes que impulsionaram a melhora dos índices. O PNSB (artigo 52, Lei Federal $n^{\circ} 11.445 / 2007$ ) tem conteúdo mínimo previsto em lei, abrangendo objetivos e metas de universalização, proposição e planejamento de programas, projetos e ações juntamente a uma avaliação sistemática. Dessa forma, exemplifica áreas prioritárias para as ações da União, determinando que o planejamento envolvido na elaboração desses documentos considere a perspectiva de 20 anos, devendo ser avaliados anualmente e revisados a cada quatro anos (BELCHIOR, 2020).

A qualidade da água se torna cada vez mais degradada em muitas áreas por problemas como poluição e saneamento inadequado. Com isso, os custos de tratamento da água aumentam e os riscos à saúde pública são potencializados. Mesmo quando há água potável disponível em quantidade suficiente, ela não está à disposição de todos por fatores econômicos que limitam o acesso (NEXO, 2018).

Os serviços que integram o saneamento básico são de grande complexidade e necessitam de alterações e mudanças para que sejam efetivados e contemplem toda a população brasileira. Para melhorar o setor, se comporta a todos, poderia existir maior fiscalização das obras que estão em construção como nos serviços de drenagem de água pluvial urbana e saneamento básico. Os serviços de abastecimento de água poderiam ser estendidos a todos aqueles que ainda não possuem água potável. Na gestão de resíduos, precisaria ser trabalhada a regulação no atendimento urbano nos bairros, além do encerramento dos lixões e espaços que servem de acondicionamento inadequado de resíduo (COSTA e PINHEIRO, 2018).

A Agência Nacional de Águas (ANA) deve desempenhar papel central no saneamento brasileiro a partir do novo marco legal do setor. A ANA deve ser a ferramenta usada pelo governo federal para centralizar a regulação do setor de saneamento. A ela caberá formular as chamadas "normas de referência", que orientarão a atuação das empresas prestadoras de serviços e das agências reguladoras locais. Entre as funções que devem entrar no escopo da ANA está o estabelecimento dos padrões de qualidade e eficiência que serão adotados no saneamento básico e a determinação das tarifas a serem cobradas dos consumidores dos serviços. A agência também deve padronizar as diferentes metas do setor, considerando as condições de cobertura e viabilidade da prestação de serviços em cada local (NEXO JORNAL, 2019). 


\subsection{Privatização dos serviços e as tarifas praticadas}

O então PL 4162, de relatoria do senador Tasso Jereissati (PSDB-CE), foi defendido como o único caminho para alcançar a universalização do saneamento. $O$ texto da lei determina o fornecimento de água potável a 99\% dos lares, assim como a coleta e tratamento de esgoto a 90\%, até 2033. Entretanto, experiências internacionais explicitam o fracasso da iniciativa privada no setor. Conforme aponta estudo do Instituto Transnacional (TNI), centro de pesquisas com sede na Holanda, de 2000 a 2019, 312 cidades em 36 países reestatizaram seus serviços de tratamento de água e esgoto (Figura 2). Entre elas, Paris (França), Berlim (Alemanha), Buenos Aires (Argentina) e La Paz (Bolívia). As quebras ou não renovações de contratos ocorreram após tarifas muito altas e promessas de universalização não cumpridas, consequências da busca pelos altos retornos financeiros (BRASIL DE FATO, 2020a).

A ideia de que privatizações estão relacionadas à eficiência de uma empresa é uma falácia e não se sustenta. A afirmação é da pesquisadora Suyá Quintslr, do Instituto de Pesquisa e Planejamento Urbano e Regional, da Universidade Federal do Rio de Janeiro (IPPUR/UFRJ), sobre os argumentos de defesa das privatizações dos serviços de água e esgoto, incluindo a Cedae. Para a pesquisadora, em um contexto de grande desigualdade social como o nosso, existe a "possibilidade do acirramento das diferenças de acesso aos serviços", algo que uma empresa pública não pode ignorar (BRASIL DE FATO, 2020b).

\footnotetext{
"Existe uma tendência amplamente documentada dos operadores privados optarem por investir nos serviços nas áreas nas quais eles são lucrativos, deixando as redes e infraestruturas das áreas habitadas pela população com reduzida capacidade de pagamento se degradarem", avalia a professora do IPPUR/UFRJ.
}

Em uma contextualização histórica, os processos iniciam-se dada a crise política e econômica na década de 1980, com os governos federais e estaduais abrindo o processo de privatização das empresas públicas, bem como a extinção de programas da pasta econômica como o PLANASA. Esse foi o terreno preparado para que as portas fossem abertas ao neoliberalismo no país e, assim, o discurso sobre a qualidade e ampliação dos serviços públicos, agora executados por empresas privadas, fosse disseminado, logrando melhorias e universalização de acesso.

Para determinados segmentos populacionais, a desigualdade no acesso à água tratada é uma realidade objetiva aos que residem em áreas periféricas, e que se veem apartados do restante da cidade no tocante ao usufruto de bens coletivos produzidos socialmente. Além disso, a gestão privada dos serviços de abastecimento urbano de água tem ampliado e intensificado essa desigualdade. A segregação socioespacial previamente existente impede que haja universalização do acesso à água tratada, na medida em que os potenciais beneficiários não conseguem arcar com os custos gerados pelo processo de privatização. Nesse sentido, a gestão privada dos serviços de água e esgoto no município tende a reforçar a apartação e diferenciação social entre os consumidores, ao contrário do que defendem os idealizadores desse tipo de redução da ação do estado. (GUIMARÃES, 2012).

Enquanto iniciativas para privatizar sistemas de saneamento avançam no Brasil, um estudo indica que esforços para fazer exatamente o inverso - devolver a gestão do tratamento e fornecimento de água às mãos públicas - continua a ser tendência global crescente. Em geral, observa-se que as cidades estão voltando atrás porque constatam que as privatizações ou PPPs acarretam tarifas muito altas, não cumprem promessas feitas inicialmente e operam com falta de transparência, entre uma série de problemas constatados (BBC BRASIL, 2017).

O modelo de PPPs foi responsável pela universalização do saneamento em diversos países do mundo. $\mathrm{Na}$ Alemanha, aproximadamente $99 \%$ da população tem acesso à água e ao esgoto tratado e as empresas privadas possuem $40 \%$ de participação no setor. No Chile, a iniciativa privada é responsável por $94 \%$ do atendimento à população urbana e com índice de tratamento próximo dos $100 \%$. Nem sempre, porém, o modelo é sinônimo de sucesso (VEJA, 2020). 

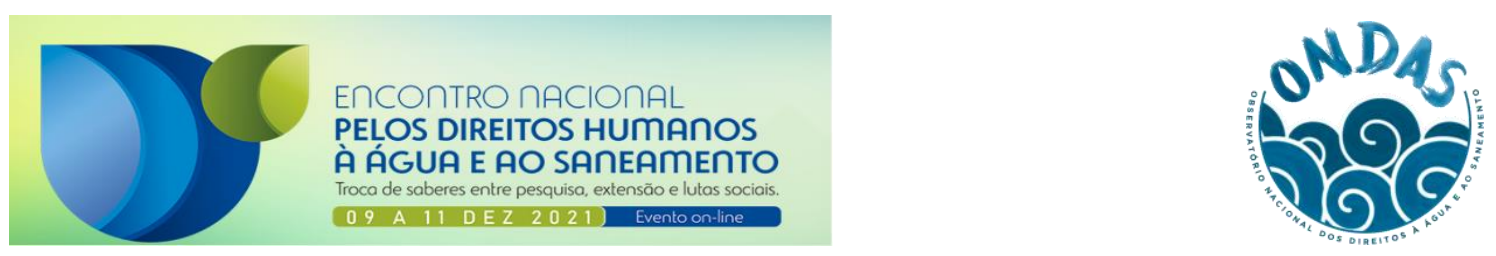

Um dos principais argumentos apresentados pelos proponentes da privatização e PPPs para convencer as autoridades públicas é que suas soluções são mais econômicas do que a gestão pública. No entanto, isso foi refutado vez após vez, por experiência. Contratação de empresa privada para entrega de um serviço envolve custos extras imediatos por causa da transferência de dinheiro às empresas-mãe e acionistas. De acordo com privatizadores, esses custos extras são compensados pela "inovação" e "economia de escala" feitas por grandes empresas, o que naturalmente seria mais eficiente do que serviços públicos. Mas a supostamente superior "inovação" e "eficiência" do setor privado, muitas vezes, se resumem à implementação básica - e no longo prazo, muitas vezes, prejudicial - de políticas de corte de custos (TNI, 2017).

A Figura 2 demonstra a ocorrência de inúmeras experiências internacionais negativas, conforme estudo mencionado do TNI.

Figura 2: Mais de 1.600 cidades ao redor do mundo agiram para colocar os serviços públicos sob controle público.

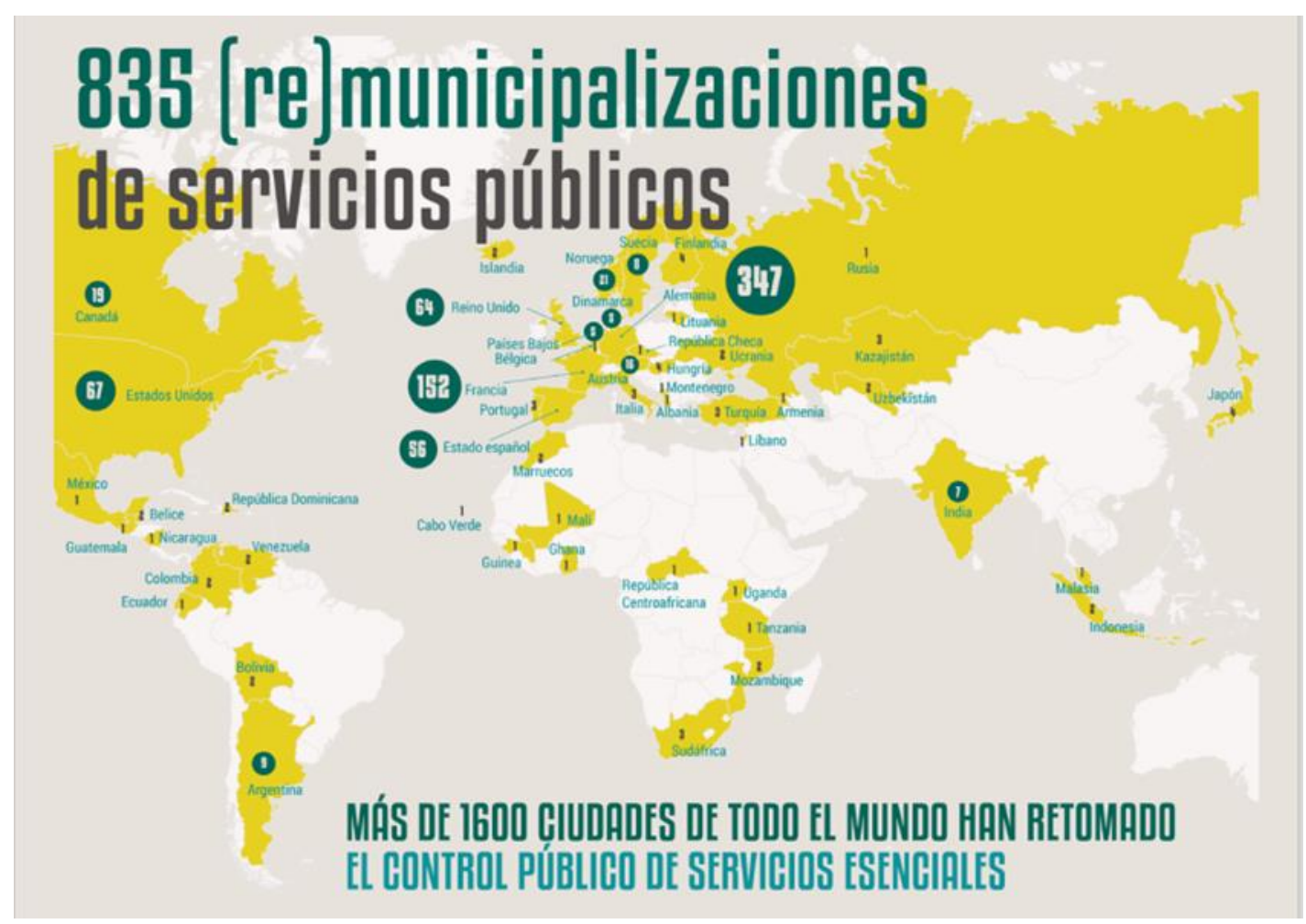

Fonte: TNI, 2017

A remunicipalização acontece em cidades pequenas e capitais de todo o planeta, seguindo vários modelos de titularidade pública e com diferentes níveis de envolvimento dos cidadãos e trabalhadores. Há muitas motivações por trás das iniciativas de remunicipalização: o objetivo de acabar com os abusos do setor privado em matéria de violações dos direitos laborais; o desejo de recuperar o domínio sobre a economia e os recursos locais; a vontade de providenciar serviços acessíveis às pessoas; a intenção de implementar estratégias ambiciosas, por exemplo, para a transição energética ou para o ambiente. Em contradição com a narrativa prevalecente de que os serviços públicos são demasiadamente dispendiosos, administrações locais e grupos de cidadãos demonstram que tal iniciativa dá resposta às necessidades básicas das pessoas e aos nossos desafios sociais e ambientais mais gerais. Esse movimento não é imediatamente visível na mídia ou no debate público porque está ocorrendo principalmente no nível local ou em contextos nacionais específicos e ainda 
porque os interesses poderosos no setor corporativo (e muitas vezes em governos nacionais e instituições internacionais) fingem que tais iniciativas locais não existem e que não há alternativa viável para a privatização e a austeridade (TNI, 2017).

Por causa do descontentamento popular com a privatização, as empresas privadas de água têm usado sua propaganda de marketing para encorajar as pessoas a acreditar que as PPPs são distintas da privatização; elas não são. PPP significa a transferência do controle da gestão dos serviços ao setor privado. Promoção de PPP dentro de governos continua agressiva atualmente e seus proponentes conseguiram apresentá-la como uma solução para trazer "financiamento inovador" para o setor de água. As autoridades locais e os formuladores de políticas devem ser extremamente cuidadosos ao considerar privatizações e PPPs em serviços de água. Reverter contratos privados é possível, mas não é nada fácil; envolve grandes custos, tempo e experiência (TNI, 2015).

Segundo estudo do Terraço Econômico (2019), ao se avaliar todas as informações colocadas acima relativas ao contexto do saneamento brasileiro e às experiências de privatização observadas no mundo e no Brasil, fica claro que essa medida não vem para atender aos anseios da maioria da população. A medida vem ao encontro do atendimento aos anseios de uma minoria organizada, formada por grandes empresas ligadas à construção civil e multinacionais de saneamento, que têm exercido grande influência sobre diversos setores do governo, seja no poder executivo, seja no legislativo.

\subsection{Responsabilidade, provisão, subsídios e tarifas}

No contexto da água para consumo humano e saneamento, o papel das entidades reguladoras vai além do mero policiamento. Os reguladores econômicos estão envolvidos com o financiamento e fixação de tarifas; e como tal estão em posição de influenciar a função do planeamento. Os reguladores precisam garantir que as tarifas sejam acessíveis, mas, ao mesmo tempo, que os investimentos necessários podem ser financiados e que é feita provisão adequada para manter de forma sustentável a capacidade dos sistemas e evitar a regressão. A interação entre as entidades reguladoras e os prestadores de serviços é delicada. Em um contexto de confiança mútua, as entidades reguladoras devem ser capazes de sancionar as entidades gestoras que não cumprirem as metas e normas, mas também devem estar abertas às necessidades de capacitação dessas entidades e apoiá-las nos seus esforços de melhoria do desempenho (BOS et al., 2017).

Buscando breve definição e entendimento dos conceitos, apresenta-se panorama sobre o saneamento básico no Brasil, no âmbito de sua administração e execução nas temáticas de: responsabilidade, provisão, subsídios e tarifas sociais. Todos os temas convergem sobre a discussão da privatização do saneamento básico.

Partindo da responsabilidade, encontra-se delineado por Arruda, Lima e Scalize (2016) uma análise sobre os municípios goianos que possuem como instituição responsável - pela administração e execução dos serviços de disponibilidade e tratamento de água e coleta e tratamento de esgoto órgãos públicos municipais, que podem organizar-se de três formas: autarquias; departamentos e secretarias exclusivas; ou em nenhum órgão em específico. A contribuição do artigo é tanto teórica, em relação aos conceitos, como metodológica, para replicação da mesma metodologia em outros estados brasileiros.

Os autores indicam que a baixa participação efetiva da população na elaboração, regulação e reformulação dos planos municipais de saneamento é um dos motivos pelos quais a prestação dos serviços não é executada da melhor maneira possível, descumprindo a legislação federal de número 11.445/2007 (BRASIL, 2007) e os acordos internacionais de direitos humanos para garantia de acesso à água potável e ao saneamento básico. Os problemas levantados e relatados nos municípios pesquisados abordam desde a etapa de execução do tratamento de água, o método como o consumo doméstico é mensurado e o método de cobrança pelos serviços de disponibilização e tratamento até 
o nível cultural, referente à rejeição da própria população à execução de processos de tratamento químico e físico para a água ser redistribuída.

Na mesma publicação, os autores demonstram ainda que as entidades caracterizadas como autarquias, por serem descentralizadas e possuírem maiores responsabilidades fiscais, são as que menos apresentam problemas de gestão; ao contrário das entidades centralizadas, como as secretarias e os municípios sem um órgão específico responsável. Além disso, os autores indicam a necessidade e importância da atuação de um órgão regulador para fiscalizar as atividades, sobretudo em relação às tarifas cobradas e distribuídas, buscando a universalização dos serviços de saneamento básico.

Scriptore e Toneto Júnior (2012) abordam aspectos jurídicos e econômicos do setor. Os autores indicam que o investimento em saneamento precisa ser considerado como estratégico para o desenvolvimento de um país, sobretudo no longo prazo. Trazem abordagem histórica referenciando o PLANASA, da década de 1970 (período ditatorial no Brasil), criado para eliminar o deficit de saneamento básico no país, a partir das companhias estaduais, designando a elas as responsabilidades sobre o serviço.

Como indicado no artigo de Arruda, Lima e Scalize (2016), a preocupação e o cuidado ao disponibilizar os dados referentes ao saneamento básico (seja por município, autarquias ou empresas privadas) é o melhor caminho para que a regulação dos serviços seja passível de realização (por entidades fiscais e pela própria população), sobretudo na plataforma do SNIS. Nas análises, os autores demonstram algumas hipóteses, por meio de indicadores, sobre as condições de exercício da função pelas empresas privadas e públicas. Em relação às empresas públicas, os autores indicam que estas teriam: a) melhor desempenho no atendimento total de água e esgoto, por terem como atributo o cumprimento de uma função social; b) quadro de funcionários mais inchado; c) menor número de tarifas por possuir maiores facilidades tributárias; d) maiores perdas de faturamento e por distribuição; e e) o maior atendimento (percentual de atendimentos) é observado nas públicas locais, em comparação às privadas e regionais.

Em relação às empresas privadas, os destaques são: a) maiores tarifas aplicadas; b) melhores indicadores financeiros; c) sacrifício da qualidade dos serviços em função da diminuição dos custos; d) maiores investimentos por terem a opção de endividamento (importante ressaltar a possibilidade alta de não cumprimento desses empréstimos feitos junto ao estado ou a algum banco estatal); e) aplicam tarifas maiores e possuem menores perdas por distribuição (devido ao rigoroso controle interno) resultando em melhores desempenhos financeiros. Importante ressaltar a condição de que as empresas privadas acumulam não apenas pelas tarifas aplicadas à população, mas também em outros setores como nos já citados empréstimos feitos com subsídios públicos, exploração da mão de obra empregada, fragmentação dos serviços, entre outros.

Discussão sobre tarifas sociais pode ser encontrada no estudo de Moretti e Britto (2021). No prefácio, Silva (2021) concebe o conceito de acessibilidade econômica para fomentar o debate da importância da tarifa social, que possui origem em uma publicação da ONU. A necessidade do debate se faz pela condição problemática de emprego da tarifa social em muitos municípios e estados brasileiros, burocratizado pelas empresas prestadoras do serviço de saneamento, que buscam mais elementos além do CadÚnico para categorizar essa parcela da população, o que exclui grande parcela da população que não tem acesso à plataforma (seja por desconhecimento, isolamento geográfico, situação de rua, analfabetismo, entre outros). Além disso, a perspectiva em relação à tarifa social é de que seja política pública e não apenas uma possibilidade. Os serviços de saneamento (água tratada e esgoto) devem ser executados independentemente da capacidade de pagamento e das condições de moradia da população, sobretudo a mais carente; algo que não acontece. Assim, a publicação levanta questões como "quais são as condições mínimas de manutenção da saúde das pessoas que são atingidas pela restrição no uso da água e esgotamento pelos cortes?”. 
Na mesma publicação, Aguiar e Moretti (2021) relacionam diretamente a condição de acesso ao saneamento básico à proteção da saúde pública; além da condição dos DH fundamentais e da condição de que o que se paga pelo acesso ao saneamento básico não pode excluir o acesso aos outros DH fundamentais, como alimentação e moradia. Tudo isso é visto em teoria, sobretudo no Brasil. Além disso, os autores identificaram que as tarifas cobradas pelas prestadoras privadas dos serviços de saneamento são maiores e há maior burocratização para o emprego das tarifas sociais, elencando características específicas que dificultam o acesso ao DH. Para que a universalização aconteça, os autores identificam a necessidade de: equidade, responsabilidade, sustentabilidade, participação, transparência e acesso à informação; para depois as modificações nas estruturas de distribuição.

O impacto positivo para a população com as privatizações dos serviços de saneamento é o maior controle de qualidade do serviço ofertado, visto que os contratos firmados com a iniciativa privada são regulados e fiscalizados. Outro fator que conta positivamente são os investimentos em tecnologias e produtos para melhorar os serviços à população. Contudo, por conta dos esforços e investimentos citados acima, as contas poderão sofrer reajustes (EOS, 2021).

Finalmente, serviços de abastecimento de água e entidades reguladoras podem fortalecer seus compromissos e das suas equipes para a realização dos DHAS por meio da adoção de um código coletivo de boas práticas, como a Carta de Bona da International Water Association para Abastecimento Seguro de Água para Consumo Humano.

\section{CONCLUSÃO}

Questiona-se como a regulação do saneamento básico será executada com o caminhar a passos rápidos da privatização dos serviços do setor. O Brasil foi um dos 122 países signatários que votaram favoravelmente para que a água e o saneamento fossem considerados direitos humanos; o que contradiz as condições encontradas hoje no setor de saneamento. A busca pela universalização dos serviços de saneamento básico no país é uma equação de difícil igualdade, demandando amplo esforço político, que envolve o poder público e a sociedade, no sentido de afirmar e validar os serviços de saneamento básico para toda a população.

O estudo do Instituto Transnacional, dentre outros, e as experiências brasileiras e estrangeiras mostram maior rentabilidade por parte dos prestadores privados e maior alcance de metas sociais positivas pelos prestadores públicos dos serviços de saneamento. Porém, entendemos que a lucratividade junto a serviços básicos essenciais à vida é uma barreira importante a ser superada.

Não há unanimidade quanto à privatização da água e do saneamento básico. Ainda que o debate pelo olhar econômico e administrativo seja relevante, a origem da discussão está no acesso à água potável por qualquer ser humano e, portanto, um debate economicista não deveria ocupar o lugar de maior relevância, mas, sim, a importância e a garantia do direito humano e da necessidade biológica de acesso à água.

Pode-se aprender lições preciosas partindo das experiências vividas por outros países que remunicipalizaram com sucesso seus serviços de abastecimento de água e de saneamento básico. Essa mudança trouxe eficácia operacional, aumento do investimento em sistemas de água e níveis mais elevados de transparência.

\section{REFERÊNCIAS}

AGUIAR, Alex Moura de Souza; MORETTI, Ricardo de Sousa Introdução: a Tarifa Social e o direito humano à água e ao saneamento. In: MORETTI, Ricardo de Sousa; BRITTO, Ana Lucia 
ÁGUA COMO DIREITO: Tarifa Social como Estratégia para a Acessibilidade Econômica / organização Ricardo de Sousa Moretti, Ana Lucia Britto. - 1. ed. - Rio de Janeiro: Letra Capital; Brasília [DF]: ONDAS - Observatório Nacional dos Direitos à Água e ao Saneamento, 2021.

ALBUQUerQue,C. Manual Prático para a Realização dos Direitos Humanos à Água e ao Saneamento pela Relatora Especial da ONU, Catarina De Albuquerque. Portugal, 2014. Disponível em: https://www.ohchr.org/Documents/Issues/Water/Handbook/Book1_intro_pt.pdf

ARRUDA, Poliana N.; LIMA, Aline S.; SCALIZE, Paulo S. Gestão dos serviços públicos de água e esgoto operados por municípios em Goiás, GO, Brasil. Rev. Ambiente. Água, vol 11 n. 2, Taubaté - Abril/Jun 2016. Disponível em: 〈https://doi.org/10.4136/ambi-agua.1739〉.

BBC BRASIL. Enquanto Rio privatiza, por que Paris, Berlim e outras 265 cidades reestatizaram saneamento? 23.jun.2017. Disponível em: https://www.bbc.com/portuguese/brasil40379053. Acesso em: 28.09.2017.

BELCHIOR, W. S. Os impactos do Novo Marco Legal do Saneamento. Revista Consultor Jurídico, 19/08/2020.

BORDALO, C. A. O paradoxo da água na região das águas: o caso da Amazônia brasileira. Geousp - Espaço e Tempo, v. 21, n. 1, p. 120-137, abril. 2017.

BRASIL. Lei ${ }^{\circ}$ 9.433, de 8 de janeiro de 1997. Institui a Política Nacional de Recursos Hídricos, cria o Sistema Nacional de Gerenciamento de Recursos Hídricos, regulamenta o inciso XIX do art. 21 da Constituição Federal, e altera o art. $1^{\circ}$ da Lei n ${ }^{\circ}$ 8.001, de 13 de março de 1990, que modificou a Lei $\mathrm{n}^{\circ}$ 7.990, de 28 de dezembro de 1989 . Disponível em: 〈http://www.planalto.gov.br/ccivil_03/leis/L9433.htm>. Acesso em: 14/5/2021.

BRASIL. Casa Civil. Subchefia para Assuntos Jurídicos. Emenda Constitucional No 90, de 15 de setembro de $2015 . \quad$ Disponível em http://www.planalto.gov.br/ccivil_03/constituicao/emendas/emc/emc90.htm Acesso em: agosto de 2021.

BRASIL DE FATO. Exemplos no Brasil e no mundo mostram fracasso da privatização do saneamento básico. Em 20 anos, 312 cidades em 36 países reestatizaram o tratamento de água e esgoto após piora no serviço e preços abusivos. 28/07/2020. Disponível em: https://www.brasildefato.com.br/2020/07/28/exemplos-no-brasil-e-no-mundo-mostram-fracasso-daprivatizacao-do-saneamento-basico. Acesso em: 28/09/2021.

BRASIL DE FATO. Há dez anos, ONU declarava acesso à água e saneamento como direito humano. 28/07/2020a. Disponível em: https://www.brasildefato.com.br/2020/07/28/ha-dez-anosonu-declarava-acesso-a-agua-e-saneamento-como-direito-humano. Acesso em: 27/07/2021.

BRASIL DE FATO. "Só gestão pública reduz desigualdade no acesso ao saneamento", afirma pesquisadora. Segundo Suyá Quintslr, do IPPUR/UFRJ, investir em infraestrutura nas periferias é incompatível com a operação privada. 22.07.2020b. Disponível em: https://brasildefato/2020/07/22/so-gestao-publica-reduz-desigualdade-no-acesso-ao-saneamenoafirma-pesquisadora . Acesso em: 22/07/2021.

CAETANO, GM. Projeto de tratamento de água de abastecimento para uma cidade de 50000 mil habitantes. Trabalho de Conclusão de Curso em Engenharia Química. Niterói: Universidade Federal Fluminense, 2016. 80p.

CARLI, A. A. A água e seus instrumentos de efetividade. Campinas: Millennium, 2013, p.38 e 40. 
CARVALHO, A. P.; MORAES NETO, J. M.; LIMA, V. L. A.; SILVA, D. G. K. C. Determinação
espacial e temporal do IQA do açude Soledade em Soledade-Paraíba. Engenharia Ambiental, v. 8, n. 2 , p. $138-147,2011$.

CEPAL - Comisión Económica para América Latina y el Caribe. La ineficiencia de La desigualdad. Síntesis (LC/SES.37/4), Santiago, 2018.

COSTA, R. N. P. O cenário do Saneamento Básico no Brasil. Revista Educação Ambiental em Ação, n. 66, 06.dez.2018. Disponível em: https://www.revistaea.org/artigo.php?idartigo=3523. Acesso em: 27/07/2021.

EOS ORGANIZAÇÃO E SISTEMAS. Privatização e serviços de saneamento básico para 2021. 2021. Disponível em: https://www.eosconsultores.com.br/privatizacao-de-servicos/. Acesso em: $29 / 09 / 2021$

FAUSTINO, A. B. RAMOS, F. F. SILVA. S. M. P. Dinâmica temporal do uso e cobertura do solo na Bacia Hidrográfica do Rio Doce $(\mathrm{RN})$ com base em Sensoriamento Remoto e SIG: uma contribuição aos estudos ambientais. Revista Sociedade e Território, Natal, v. 26, n 2, pp. 18 - 30, 2014.

FERREIRA, L. E NEVES-SILVA, P. Breve Análise das Principais Características dos Municípios com Prestação Privada no Brasil. Observatório Nacional dos Direitos à Água e ao Saneamento - ONDAS. Publicado em 14 de julho de 2021. Disponível em https://ondasbrasil.org/breve-analise-das-principais-caracteristicas-dos-municipios-com-prestacaoprivada-no-brasil// Acesso em: agosto de 2021.

FREIRE, A. L. Saneamento Básico: conceito jurídico e serviços públicos. Enciclopédia Jurídica da PUCSP. Tomo Direitos Difusos e Coletivos, ed. 1, jul. 2020.

GUIMARÃES, R. M. A. B. A privatização da água e seus impactos sobre populações residindo na periferia urbana de Campos dos Goytacazes/RJ. Dissertação de Mestrado em Políticas Sociais. Campos dos Goytacazes: Universidade Estadual do Norte Fluminense, 2012.

HOFFMANN, A. C. C. Regulação e Saneamento na Lei Federal no 11.445/07. Revista Jurídica da Procuradoria Geral do Estado do Paraná, Curitiba, n. 3, p. 211-244, 2012.

LIMA, A. M. R. A. Saneamento básico - Um Direito Fundamental. Caminho para universalização. In: MIRANDA, J.; MARQUES, R. C.; SAMPAIO, P.; SAMPAIO, R. Estudos de Direito do Saneamento. Lisboa: Instituto de Ciências Jurídico-Políticas, Centro de Investigação de Direito Público, mar. 2020.

LOPES, F. B. et al. Mapa da qualidade das águas do rio Acaraú, pelo emprego do IQA e Geoprocessamento. Revista Ciência Agronômica, Universidade Federal do Ceará, v. 39, n. 3, p. 392402, jul./set. 2008 .

MACEDO, A. F. Uma análise crítica sobre a judicialização da política pública de saneamento básico no Brasil. In: MIRANDA, J.; MARQUES, R. C.; SAMPAIO, P.; SAMPAIO, R. Estudos de Direito do Saneamento. Lisboa: Instituto de Ciências Jurídico-Políticas, Centro de Investigação de Direito Público, mar. 2020.

MINISTÉRIO DAS CIDADES. Secretaria Nacional de Saneamento Ambiental - SNSA. Sistema Nacional de Informações sobre Saneamento: Diagnóstico dos Serviços de Água e Esgotos - 2016. Brasília, fev. 2018.

MORETTI, Ricardo de Sousa; BRITTO, Ana Lucia ÁGUA COMO DIREITO: Tarifa Social como Estratégia para a Acessibilidade Econômica / organização Ricardo de Sousa Moretti, Ana Lucia 
Britto. - 1. ed. - Rio de Janeiro: Letra Capital; Brasília [DF]: ONDAS - Observatório Nacional dos Direitos à Água e ao Saneamento, 2021.

MOTA, S. Introdução à Engenharia Ambiental. 5. ed. Rio de Janeiro: ABES, 2012.

NEXO JORNAL LTDA. A crescente atuação de empresas privadas na gestão de água e esgoto. Participação do setor privado no setor é defendida como saída para falta de recursos públicos. Especialistas defendem regulação e controle. 24.mar.2018. Disponível em: https://www.nexojornal.com.br/expresso/2018/03/24/A-crescente-atua\%C3\%A7\%C3\%A3o-deempresas-privadas-na-gest\%C3\%A3o-de-\%C3\%A1gua-e-esgoto. Acesso em: 28/09./021.

NEXO JORNAL LTA. O que é o novo marco legal do saneamento básico. Projeto de lei aprovado pela Câmara abre caminho para aumento da participação da iniciativa privada no setor. O 'Nexo' explicou a proposta e destrinchou os pontos mais polêmicos. 12.dez.2019. Disponível em: https://www.nexojornal.com.br/expresso/2019/12/12/O-que-\%C3\%A9-o-novo-marco-legal-dosaneamento-b\%C3\%A1sico. Acesso em: 28.09.2021.

OLIVEIRA, Cristiane F. de. A Gestão dos serviços de saneamento básico no Brasil. Scripta Nova. Revista Eletrônica de Geografia y Ciências Sociales. Barcelona, v. IX, n. 194, agosto/2005.PEDROSA, Valmir de A.; PEREIRA, Jaildo S. Gestão de serviços de águas no Brasil: da provisão pública a operação privada? Propositions. Brésil, 2000 Atelier Services urbains.

ONU - Organização das Nações Unidas. Relatório do Relator Especial sobre o direito humano à água potável e ao esgotamento sanitário. Conselho de Direitos Humanos. 30a sessão. Item 3 da agenda Promoção e proteção de todos os direitos humanos, civis, políticos, econômicos, sociais e culturais, incluindo o direito ao desenvolvimento. Assembleia Geral A/HRC/30/39, 05.ago.2015.

ONU - Organização das Nações Unidas. 2021. Direitos humanos devem orientar políticas de água e saneamento, diz relator da ONU. Disponível em: <https://nacoesunidas.org/direitos-humanosdevemorientar-politicas-de-agua-e-saneamento-diz-relator-da-onu>. Acesso em: out.2021.

ONU - Organização das Nações Unidas. Direitos humanos e a privatização dos serviços de água e esgotamento sanitário - Relatório do Relator Especial sobre os direitos humanos à água potável e ao esgotamento sanitário. Assembleia Geral 21 julho 2020 Septuagésima quinta sessão Item 72 (b) da agenda provisória A/75/208 Disponível em https://ondasbrasil.org/relatorios-sobredireito-humano-a-agua-potavel-e-ao-esgotamento-sanitario-autor-leo-heller/.

POLITIZE. Água é um direito humano? 2021. Disponível em: https://www.politize.com.br/aguadireito-humano/ . Acesso em: 19.08.2021.

RAMOS, C. S. e BRITO, A. L. A face oculta da privatização das águas. Outras Palavras. Publicado 10/06/2021. Disponível em https://outraspalavras.net/crise-brasileira/face-oculta-da-privatizacaodas-aguas/ Acesso em: agosto de 2021.

SCRIPTORE, Juliana Souza; TONETO JUNIOR, Rudnei A estrutura de provisão dos serviços de saneamento básico no Brasil: uma análise comparativa do desempenho dos provedores públicos e privados. Revista Adm. Pública. Rio de janeiro 46 (6), nov/dez, 2012. Disponível em: <https://doi.org/10.1590/S0034-76122012000600004>.

SILVA, Edson Ap A Tarifa Social e a acessibilidade econômica. In: MORETTI, Ricardo de Sousa; BRITTO, Ana Lucia ÁGUA COMO DIREITO: Tarifa Social como Estratégia para a Acessibilidade Econômica / organização Ricardo de Sousa Moretti, Ana Lucia Britto. - 1. ed. - Rio de Janeiro: Letra Capital; Brasília [DF]: ONDAS - Observatório Nacional dos Direitos à Água e ao Saneamento, 2021. 
SNIS - Sistema Nacional de Informações sobre Saneamento. Painel de Informações Saneamento Brasil. Brasília: MDR, 2019. Disponível em: https://snis.gov.br/painel-informacoes-saneamentobrasil .Acesso em: 27/07/2021.

SOUZA, S. M. L. A. P. Saga: Água é vida, privatização nunca será a solução! 2020. Disponível em: https://www.conjur.com.br/dl/saga-agua-vida-privatizacao-jamais.pdf . Acesso em: 21/08/2021.

TNI - Transnational Institute. Our public water future. The global experience with remunicipalisation. Satoko Kishimoto, Emanuele Lobina, Olivier Petitjean and Madeleine Bélanger Dumontier (eds.). Amsterdam, London, Paris, Cape Town and Brussels.

TNI - Transnational Institute. Reclaiming Public Services: How cities and citizens are turning back privatisation. june 2017. Satoko Kishimoto, Olivier Petitjean and Lavinia Steinfort (eds.). Amsterdam and Paris.

VEJA. Privatizar ou estatizar? Como o mundo lida com o saneamento básico. Novo marco do saneamento trouxe a discussão à tona; experiência internacional mostra que não há fórmula pronta. 26/06/2020. Disponível em: https://veja.abril.com.br/mundo/privatizar-ou-estatizar-como-o-mundolida-com-o-saneamento-basicol. Acesso em: 28/09/2021.

VON SPERLING, M. Introdução à qualidade das águas e ao tratamento de esgotos. 2. ed. Belo Horizonte: Editora UFMG, 1996.

World Bank. Beyond Scarcity: Water Security in the Middle East and North Africa. MENA Development Series. World Bank, Washington, 2017. 